Trabajos y Comunicaciones, 2da. Época, Nº 47, e059, enero 2018. ISSN 2346-8971

Universidad Nacional de La Plata.

Facultad de Humanidades y Ciencias de la Educación.

Departamento de Historia

\title{
Contente, Claudia. Familias en la tormenta. Tierra, familia y transmision del patrimonio en el Río de la Plata, siglos XVIII y XIX. Buenos Aires, Prometeo Libros, 2015, 228 págs.
}

\author{
María Angélica Arias * \\ * Universidad Nacional de Santiago del Estero, Argentinal \\ angiearias1980@gmail.com
}

Claudia Contente es investigadora en la Universitat Pompeu Fabra (UPF, Barcelona), y además del presente libro "Familias en la Tormenta. Tierra, familia y transmisión de patrimonio en el Río de la Plata, siglos XVIII y XIX” es autora y editora adjunta de la Revista Illes i Imperis (GRIMSE, Departamentd' Humanitats, UPF). También forma parte del equipo de investigación que organiza el Séminaired' Histoire de la Famille en la Ecole des Hautes Études en Sciences Sociales (EHESS, París), y es miembro del consejo de la International Commission for Historical Demography. Ha sido coordinadora científica del proyecto State Building in Latin America, financiado por el European Research Council (ERC). Ha editado con Juan Carlos Garavaglia "Configuraciones estatales, regiones y sociedades locales América Latina, siglos XIX-XX” (Barcelona, Editorial Bellaterra: 2011). Ha publicado artículos en revistas y capítulos de libros sobre la historia rural de River Plate, sus habitantes y actividades en los siglos in the XVIII y XIX.

Con este libro, Contente se introduce en el mundo rural de la campaña bonaerense de los siglos XVIII y XIX, poniendo especial atención en algunas familias campesinas de dos zonas puntuales: una de antigua colonización como La Matanza y otra de colonización más reciente como San Vicente. Mediante un análisis comparativo, la autora invita al lector a aproximarse a los usos y costumbres transmitidos de generación en generación entre los productores, criadores y labradores de las pampas, interiorizándose por sus diferentes modos de organización familiar, los ámbitos en

Cita sugerida: Cita sugerida: Arias, M. A. (2018). [Revisión del libro Familias en la tormenta. Tierra, familia y transmisión del patrimonio en el Río de la Plata, siglos XVIII y XIX por C. Contente]. Trabajos y Comunicaciones (47), e059. https://doi.org/10.24215/23468971e059 
los que éstos se movían y las estrategias que implementaban para defender sus intereses, fundamentalmente aquellos relacionados al plano patrimonial. Para ello, analiza ciclos de vida familiares y reconstruye algunos egos y trayectorias vitales abarcando, en algunos casos, hasta dos y tres generaciones de manera que sea posible aprehender históricamente un patrón o denominador común en términos de construcción, consolidación, preservación y, a veces, recuperación del patrimonio familiar. En este aspecto, la autora otorga a las estrategias matrimoniales entre consanguíneos y afinales (primos hermanos y ahijados que se convierten en yernos o nueras) un papel fundamental, además de dar cuenta de la existencia de una cierta relajación en las costumbres con respecto a la legislación vigente sobre matrimonios entre parientes. En este punto la autora logra aprehender y articular un proceso estructural de larga duración como el de la “descristianización de la sociedad” con otro más coyuntural de las estrategias y prácticas matrimoniales disruptivas con respecto a lo permitido y lo prohibido por la Iglesia Católica, llevadas a cabo por las familias campesinas de la campaña bonaerense.

El libro está estructurado en dos partes. Una primera, centrada en las características poblacionales de la Matanza y San Vicente, consistente en un análisis pormenorizado de los censos de 1813, 1815, 1836 y 1838, mediante los cuales logra desarrollar una visión “macroanalítica” de ambas regiones, interesada en la estructura demográfica, las corrientes migratorias, la conformación de los grupos domésticos, las diversas formas de acceso a la tierra y los tipos de explotación predominantes. Una suerte de cartografía espacial y socio-ocupacional que le posibilita rastrear las diferenciaciones sociales en el mundo rural analizado. En este sentido identifica categorías ocupacionales específicas para cada zona y las pone en relación con redes sociales más solidas y con mayor arraigo e influencia en la región. En esta parte muestra como una parte fundamental de la producción de La Matanza y San Vicente descansaba, a principios del siglo XIX, exclusivamente sobre familias campesinas. Con una mayoría de explotaciones en ambas zonas que contaban solo con mano de obra familiar. Si bien al grupo domestico se podía agregar, eventualmente, algún peón o esclavo, la incorporación de otros miembros no era predominante. En relación a la organización de la explotación, eran a la vez flexibles y complejas y se contraían y expandían según el desarrollo de las etapas vitales de la unidad, la acumulación ligada al ciclo de vida y, en una escala más amplia, según los cambios en las condiciones económicas y productivas en las que éstas evolucionaban.

El análisis de los censos también le permite reconstruir los ciclos vitales de las unidades familiares y ver su evolución en perspectiva histórica, haciendo foco en la composición de las mismas. En este sentido, Contente crea categorías propias que le permiten identificar y comparar la fuerza de trabajo en ambas zonas en distintos momentos del ciclo de vida familiar, tales como: familia corresidente, familia y peones no agregados, familia y esclavos, familia y peones agregados, familia y peones no agregados y esclavos, etc. Lo interesante de este ejercicio es que le posibilita dar cuenta de cómo va cambiando (o no) esta composición en relación con el contexto económico en el que las unidades familiares se inscribían, las actividades productivas que desarrollaban y la mano de obra que empleaban.

La segunda parte del libro es la más valiosa por su densidad y rigor heurístico y la capacidad de su hermenéutica para abarcar áreas y dimensiones de la vida familiar difíciles de aprehender en la larga duración. El entrecruzamiento de fuentes de diversa índole (testamentos, mensuras, sucesiones, 
inventarios, entre otros) junto a la información relevada de los censos, le permite a la autora introducirse de manera exhaustiva en los múltiples mecanismos que las familias de ambas zonas ponían en funcionamiento para asegurar su reproducción, profundizando en las prácticas de herencia y transmisión de la propiedad, las alianzas matrimoniales, la consanguinidad y las redes de parentesco. Identifica un denominador común en términos de estrategias matrimoniales orientadas a preservar el patrimonio que, en algunos casos se replicaron durante tres generaciones en el mismo espacio geográfico: los matrimonios entre parientes consanguíneos y de parentesco espiritual. Encuentra varios casos de casamientos entre primos hermanos (con pedido de dispensa) en donde las divisiones hereditarias, llegada la hora de repartir las tierras, se entregaban a los esposos en parcelas limítrofes de manera que pudieran unirlas y constituir una propiedad mayor. El trabajo de análisis que realiza sobre los mapas y mensuras de las propiedades campesinas (comparando mensuras de 1835 y 1872) también es un aporte valioso, ya que permite tener una visión global acerca de los modos de reparto de la tierra a lo largo del tiempo entre los herederos y sus cónyuges. En muchos casos, logra detectar alianzas entre parientes que, al ser también vecinos, permitían a las familias reagrupar tierras y recuperar partes del patrimonio que se había dividido por las herencias y sucesiones de sus antepasados. En palabras de Contente se estaría "frente a lo que Viret denomina un pool matrimonial, una especie de coalición entre familias de una misma actividad a través de una serie de matrimonios especiales (consanguíneos, dobles, cruzados) que si bien en el caso estudiado por Viret se registran en un lapso de tiempo relativamente corto (...) aquí se verifican durante al menos unos... ¡140 años!” (Contente 2015: 191). Eran uniones matrimoniales al límite del incesto que operaban como estrategias orientadas a la preservación y unión patrimonial, así como a eludir las consecuencias de fragmentación de las propiedades que imponía el sistema de herencia igualitario. Otro elemento que logra detectar es que la mayor parte de estos casamientos ocurrían entre parientes que eran propietarios de tierras, aunque sea por cantidades mínimas. Lo cual sugiere homogamia, como otra práctica predominante en las zonas estudiadas. Esta lógica de reagrupamientos de tierras da cuenta de la fuerza que tenía la autoridad paterna a la hora de concertar alianzas y diseñar estrategias matrimoniales ventajosas.

Finalmente, se puede decir que el libro está escrito en dos lenguajes diferentes pero imbricados entre sí. Por un lado una narrativa histórica amena y asequible mediante la cual los procesos globales dialogan con las singularidades históricas que componen el objeto de estudio del libro, pero además otro lenguaje, denso y abigarrado de información, que llega al lector a través de los gráficos, mapas y esquemas que la autora logra reconstruir gracias a una tarea meticulosa frente a la multiplicidad de fuentes utilizadas. 